\title{
INTEROPERABILITY ANALYSIS OF IFC-BASED DATA EXCHANGE BETWEEN HETEROGENEOUS BIM SOFTWARE
}

\author{
Huahui LAI, Xueyuan DENG*(D) \\ Department of Civil Engineering, School of Naval Architecture, Ocean and Civil Engineering, \\ Shanghai Jiao Tong University, Shanghai, China
}

Received 03 June 2018; accepted 24 August 2018

\begin{abstract}
Traditionally, the one-to-one interaction between heterogeneous software has become the most commonly used method for multi-disciplinary collaboration in building projects, resulting in numerous data interfaces, different data formats, and inefficient collaboration. As the prevalence of Building Information Modeling (BIM) increases in building projects, it is expected that the exchange of Industry Foundation Classes (IFC)-based data can smoothly take place between heterogeneous BIM software. However, interoperability issues frequently occur during bidirectional data exchanges using IFC. Hence, a data interoperability experiment, including architectural, structural and MEP models from a practical project, was conducted to analyze these issues in the process of data import and re-export between heterogeneous software. According to the results, the fundamental causes of interoperability issues can be concluded as follows: (a) software tools cannot well interpret several objects belonging to other disciplines due to the difference in domain knowledge; (b) software tools have diverse methods to represent the same geometry, properties and relations, leading to inconsistent model data. Furthermore, this paper presents a suggested method for improving the existing bidirectional data sharing and exchange: BIM software tools export models using IFC format, and these IFC models are imported into a common IFC-based BIM platform for data interoperability.
\end{abstract}

Keywords: Building Information Modeling (BIM), Industry Foundation Classes (IFC), data interoperability, interoperability issues, multiple disciplines, BIM software.

\section{Introduction}

In the architecture, engineering, construction and facility management (AEC/FM) industry, each discipline has its own domain knowledge. Users from various disciplines select diverse software tools for their own business tasks and then collaborate with other users for interoperability. Interoperability in practical projects involves many aspects. Chen et al. (2008) classified interoperability concerns into four areas: data, services, processes, and business. The data interoperability refers to the data sharing and exchange between heterogeneous BIM software, and it provides a base to facilitate interoperability of other concerns. However, the issues of data interoperability are still common in the AEC/FM industry.

Traditional data interoperability between diverse software tools is limited to a point-to-point direct conversion based on proprietary data formats, resulting in various "Information Islands" throughout the building lifecycle, as shown in Figure 1(a). As building projects become more complicated, the traditional method hardly meets the increasing needs of data sharing and exchange. For this purpose, BIM technology was introduced based on the concept of creating, storing and managing a great deal of information throughout the building lifecycle in an integrated way (Eastman et al. 2011). BIM software tools from different disciplines are widely applied to building projects (Liao, Teo 2017). Due to multiple disciplines, data sharing and exchange between diverse software tools become an inevitable need, and a public and rich data format is necessary for data interoperability (Tolman 1999; Ramaji, Memari 2018). Consequently, IFC schema was developed to support data sharing and exchange. According to a nonexhaustive survey, over 200 software tools have import or export capabilities of IFC data models (BuildingSMART 2013). After two decades of development, IFC has become a de facto standard for data interoperability between heterogeneous software tools (Olawumi et al. 2017). As

${ }^{*}$ Corresponding author. E-mail: dengxy@sjtu.edu.cn 
depicted in Figure 1(b), IFC schema acts as a medium for bidirectional data sharing and exchange between heterogeneous software. Sometimes software tools require data models from other disciplines to fulfil their own business tasks, and it is inevitable that software tools import the required models created by other software. Subsequently, these imported models may be re-exported as new IFC models for other business tasks. For example, a structural engineer imports the architectural model for structural design and analysis, and then exports a new model to the architect for collaborative design. However, when the IFC data format is used for BIM interoperability in practical projects, interoperability issues (Kam et al. 2002; Oh et al. 2015; Taher 2016), such as data loss and misrepresentation, commonly arise. It results in a misunderstanding that IFC schema cannot be a data standard for BIM interoperability.

Data interoperability is a process of data import and export between heterogeneous software tools. During this process, a software tool exports a created model as IFC format for data sharing and exchange, and the other one imports this IFC model for business tasks. This process includes two mappings (Ma et al. 2006; Lee 2011): (1) one mapping from the internal schemas of software tools to IFC models for export, and (2) the other from IFC models to internal schemas for import. Interoperability issues are likely to arise if either of mappings is wrong. For efficient interoperability, most existing studies suggest the improvement of IFC schema and the development of IFC data interfaces of software tools. These efforts are useful for data interoperability, but do not address interoperability issues fundamentally. In this paper, a data interoperability experiment between software tools was carried out, and then the causes of interoperability issues were analyzed at the IFC data level. Finally, a suggested method for data interoperability was discussed.

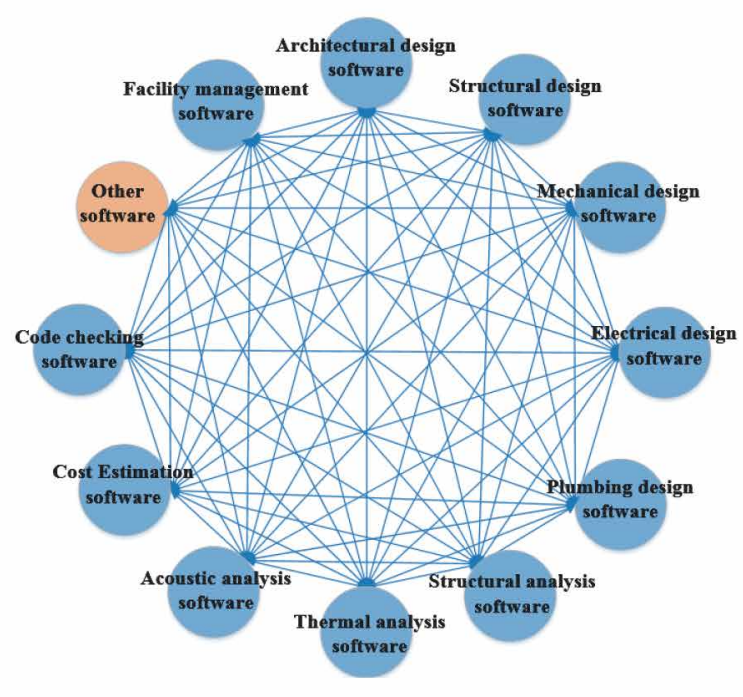

(a) Traditional method

\section{Literature review}

\subsection{Official IFC certification}

BuildingSMART adopts IFC $2 \times 3$ Coordination View V2.0 as a benchmark template to validate the IFC import and export capabilities of software tools. To date, 30 software tools have been certified for IFC import, 23 tools for IFC export, and only 14 tools passed both import and export certification (BuildingSMART 2018). Numerous software tools still need to pass the official certification for the effective support of IFC models. Furthermore, the IFC export certification can be divided into three aspects: architecture, structure, and mechanical, electrical \& plumbing (MEP) (BuildingSMART 2010).

The official IFC certification process includes two steps (Lipman et al. 2011). Step 1 includes a range of object-level models, such as beams, columns, slabs, and walls. Due to the building complexity, it is impossible for software tools to test all objects, so the most common objects are selected to test in the certification process. In Step 2, two or three project models, composed of most objects in Step 1, are used for a further certification. The certification process is largely limited to "standard objects" (Kiviniemi 2008). If complex objects are exchanged in IFC format, software tools may not guarantee lossless data exchange, even if these software tools are IFC certified. In other words, the certification process is "more of a test of the ability to exchange information via IFCs rather than the quality of the exchange" (Lipman et al. 2011).

\subsection{Related studies on data interoperability}

Data sharing and exchange is one of the key factors of collaboration throughout the building lifecycle. Various efforts from both academia and industry have been devoted to addressing current problems in data interoperability between heterogeneous software tools.

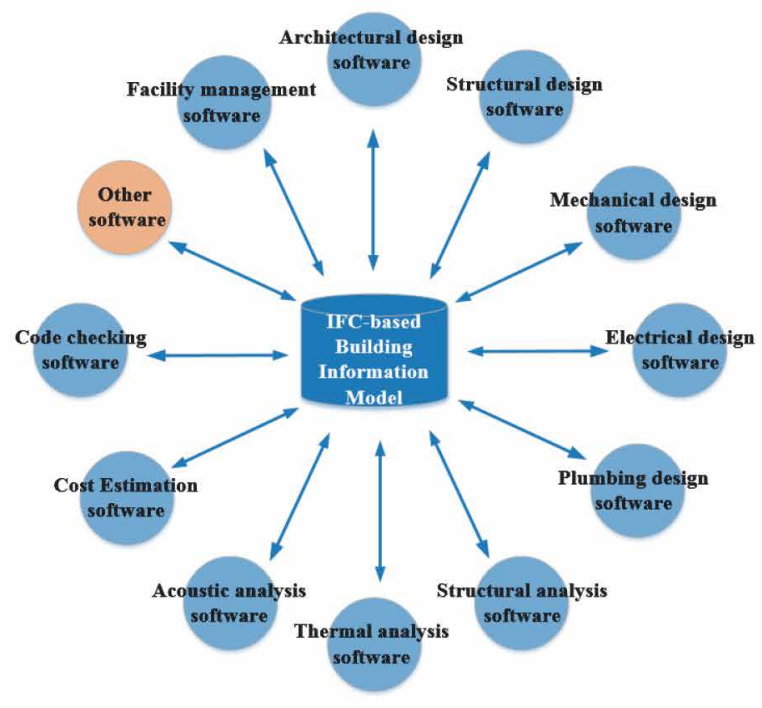

(b) BIM-based method

Figure 1. Data interoperability between various software tools 
Table 1. A non-exhaustive list of studies related to data interoperability

\begin{tabular}{|c|c|c|c|c|c|}
\hline & Test tool & Test model & Test criteria & $\begin{array}{c}\text { Analysis } \\
\text { method }\end{array}$ & Test result \\
\hline $\begin{array}{l}\text { Pazlar } \\
\text { and Turk } \\
(2008)\end{array}$ & $\begin{array}{l}\text { Architectural Desktop } \\
\text { 2005, AllPlan } \\
\text { Architecture } 2005 \text { and } \\
\text { ArchiCAD } 9\end{array}$ & $\begin{array}{l}\text { Different walls; } \\
\text { four architectural } \\
\text { models }\end{array}$ & $\begin{array}{l}\text { Wall: file size, total } \\
\text { entities, GUID, } \\
\text { direction, shape; } \\
\text { Architectural } \\
\text { model: total } \\
\text { entities, entity } \\
\text { type }\end{array}$ & $\begin{array}{l}\text { Visual } \\
\text { inspection } \\
\text { and manual } \\
\text { comparison }\end{array}$ & $\begin{array}{l}\text { Wall: differences in } \\
\text { physical file size, GUID, } \\
\text { number of objects, shape } \\
\text { representation, etc. } \\
\text { Architectural model: } \\
\text { missing GUID, geometric } \\
\text { misrepresentation, missing } \\
\text { or new material, etc. }\end{array}$ \\
\hline $\begin{array}{l}\text { Jeong } \\
\text { et al. } \\
(2009)\end{array}$ & $\begin{array}{l}\text { ArchiCAD 10.0, } \\
\text { Bentley Architecture } \\
\text { 8, Digital Project v1 } \\
\text { R3, Revit Building 9.1, } \\
\text { Tekla Structures 13 } \\
\text { and StructureWorks } \\
\text { Precast }\end{array}$ & $\begin{array}{l}\text { Some structural } \\
\text { elements, including } \\
\text { precast concrete, steel } \\
\text { and cast-in-place } \\
\text { reinforced concrete } \\
\text { members }\end{array}$ & $\begin{array}{l}\text { Geometry, } \\
\text { location, shape, } \\
\text { entity type, total } \\
\text { entities, property } \\
\text { set }\end{array}$ & $\begin{array}{l}\text { Visual } \\
\text { inspection } \\
\text { using } \\
\text { textual and } \\
\text { graphic } \\
\text { viewers }\end{array}$ & $\begin{array}{l}\text { Loss of objects, } \\
\text { inconsistent object } \\
\text { types, geometric } \\
\text { misrepresentation, loss } \\
\text { of parametric rules and } \\
\text { properties, etc. }\end{array}$ \\
\hline $\begin{array}{l}\text { Choi } \\
\text { and Kim } \\
(2011)\end{array}$ & $\begin{array}{l}\text { Revit Architecture, } \\
\text { ArchiCAD, Digital } \\
\text { Project and Solibri } \\
\text { Model Checker }\end{array}$ & $\begin{array}{l}\text { Architectural objects: } \\
\text { wall, window, door, } \\
\text { slab, and space }\end{array}$ & $\begin{array}{l}\text { Geometry, } \\
\text { property set }\end{array}$ & No mention & $\begin{array}{l}\text { Differences in name } \\
\text { and type value, missing } \\
\text { property set, etc. }\end{array}$ \\
\hline $\begin{array}{l}\text { Golabchi } \\
\text { and } \\
\text { Kamat } \\
(2013)\end{array}$ & $\begin{array}{l}\text { Bentley Microstation } \\
\text { V8i and Revit } 2012\end{array}$ & $\begin{array}{l}\text { Some architectural } \\
\text { elements, such as } \\
\text { walls, beams, columns, } \\
\text { and doors }\end{array}$ & $\begin{array}{l}\text { Geometry, } \\
\text { property }\end{array}$ & $\begin{array}{l}\text { Visual } \\
\text { inspection }\end{array}$ & $\begin{array}{l}\text { Loss of properties, missing } \\
\text { some elements, etc. }\end{array}$ \\
\hline $\begin{array}{l}\text { Nizam } \\
\text { and } \\
\text { Zhang } \\
(2015)\end{array}$ & Revit and Tekla & $\begin{array}{l}\text { A room with four } \\
\text { walls, two slabs, } \\
\text { four columns, two } \\
\text { windows, and a door; } \\
\text { A building with slabs, } \\
\text { walls, stairs, railings, } \\
\text { furniture, openings, } \\
\text { and doors }\end{array}$ & $\begin{array}{l}\text { File size, IFC } \\
\text { instances, object } \\
\text { types, attribute } \\
\text { values, schema } \\
\text { version }\end{array}$ & $\begin{array}{l}\text { Visual } \\
\text { inspection } \\
\text { and } \\
\text { automatic } \\
\text { analysis } \\
\text { using file } \\
\text { analyzer }\end{array}$ & $\begin{array}{l}\text { Inconsistent object types, } \\
\text { differing numbers of } \\
\text { instances, missing or new } \\
\text { values, loss of numerical } \\
\text { precision, reference } \\
\text { number differences, etc. }\end{array}$ \\
\hline $\begin{array}{l}\text { Sibenik } \\
(2016)\end{array}$ & $\begin{array}{l}\text { Allplan 2016, } \\
\text { ArchiCAD 19, Revit } \\
\text { 2016, SCIA Engineer } \\
15.3 \text { and RFEM } 5.05\end{array}$ & $\begin{array}{l}\text { Linear elements: } \\
\text { columns; Planar } \\
\text { elements: slabs, } \\
\text { roofs, and walls; } \\
\text { Connectivity; } \\
\text { Foundations }\end{array}$ & $\begin{array}{l}\text { Geometry, } \\
\text { element property }\end{array}$ & $\begin{array}{l}\text { Visual } \\
\text { inspection }\end{array}$ & $\begin{array}{l}\text { Different geometry } \\
\text { interpretation, inconsistent } \\
\text { object types, missing } \\
\text { property, etc. }\end{array}$ \\
\hline $\begin{array}{l}\text { Muller } \\
\text { et al. } \\
(2017)\end{array}$ & $\begin{array}{l}\text { Revit, TQS and IFC } \\
\text { Model Viewer }\end{array}$ & $\begin{array}{l}\text { A structural model } \\
\text { with beams, slabs, } \\
\text { columns, stairs, and } \\
\text { ramps }\end{array}$ & $\begin{array}{l}\text { Material/type, } \\
\text { object placement, } \\
\text { GUID, geometry }\end{array}$ & $\begin{array}{l}\text { Visual } \\
\text { inspection } \\
\text { and } \\
\text { evaluation } \\
\text { using scores }\end{array}$ & $\begin{array}{l}\text { Geometric } \\
\text { misrepresentation, loss of } \\
\text { material and load, new } \\
\text { GUIDs, etc. }\end{array}$ \\
\hline
\end{tabular}

Table 1 summarizes several studies on data interoperability based on IFC schema. According to different types of test criteria, visual inspection and some specific analysis tools (e.g., IFC file analyzer) were used when analyzing interoperability issues. Furthermore, these test results demonstrate that data loss and misrepresentation is common during data sharing and exchange using IFC format, such as missing objects, geometric misrepresentation, and inconsistent object types. It is noted that these studies mainly focus on architectural and/or structural models. To track the differences between IFC files during data sharing and exchange, several tools for quantitative analysis were developed, such as EXPRESS Evaluation System (EVASYS)
(Ma et al. 2006), Compare P21 (Lee et al. 2011), and IFCdiff (Shi et al. 2018). These efforts provided a reference to analyze the causes of interoperability issues.

Some researchers (Sanguinetti et al. 2012; Oh et al. 2015) point out that the cause of such issues is the incomplete mapping between software native models and IFC models. Hence, the quality improvement of IFC interfaces in software tools is recommended. Additionally, other researchers attempted to study how to improve data interoperability in specific domains. Karan and Irizarry (2015) extended the interoperability across the geospatial and BIM domains by using semantic web technology and ontologies of construction operations. Ramaji and 
Memari (2016) developed an interpreted information exchange method to interpret the structural analytical model from the architectural model. Kim and Yu (2016) proposed a segmentation process to divide curved walls in IFC models into segmented straight walls for building energy analysis. Hu et al. (2017) utilized several solutions, such as the logic chain and a transformation algorithm from BIM to Geographic Information System (GIS), to promote interoperability between MEP-based documents and intelligent MEP models.

Although plenty of research work has been conducted to improve data interoperability between heterogeneous software tools, interoperability issues do exist in the AEC/ FM industry - at least it is not as accurate as users expected. To summarize, some problems that need to be solved are listed as follows:

1. The AEC/FM industry involves interdisciplinary data exchanges between heterogeneous software tools. Most test models in previous studies were limited to common architectural and/or structural objects, and there were seldom test models from other disciplines, for example, MEP models.

2. Most studies mainly presented the errors and misrepresentation in the interoperability tests, but few of them analyzed in detail the causes of poor interoperability from the views of software and IFC schema.

3. Some studies concluded with several recommendations for improved work, such as the improvement of IFC schema and software data interface. It requires significant effort and broad support from domain experts and software developers. These recommendations are beneficial to improve data interoperability to some extent, but current interoperability issues are yet to be solved fundamentally.

4. Although some methodologies (such as the ontology) have been developed to improve data sharing and exchange in specific domains, interoperability issues between heterogeneous software tools are yet to be solved, which still exist in other domains. Hence, an in-depth analysis of data interoperability in the AEC/FM industry is of theoretical and applied value.

To solve these problems, an experiment of importing and exporting three types of models (including architectural, structural and MEP models) was conducted to look for interoperability issues. The causes of these issues would be further analyzed at the IFC data level. In addition, a suggested IFC-based method was proposed for improving the current process of data sharing and exchange.

\section{Method of data interoperability experiment}

\subsection{Data interoperability experiment}

In project collaboration, building information is required to share and exchange between various disciplines, such as architecture, structure, and MEP. To date, a large number of software tools have been developed for diverse domains in the AEC/FM industry. According to a survey (Kiviniemi et al. 2008), ArchiCAD, Tekla Structures, and MagiCAD are popular software tools in the architectural, structural, and MEP domains, respectively. Further, ArchiCAD has passed the IFC certification process in the architectural domain, Tekla Structures is IFC-certified for the structural domain, and MagiCAD for MEP (BuildingSMART 2018). Therefore, these three BIM software tools were selected to conduct the interoperability experiment between multiple disciplines. This experiment based on limited software tools cannot capture all interoperability issues, but major interoperability issues can be displayed because these tools are prevalent in practice. Moreover, an IFC Platform, which was developed by the authors, was also tested in this experiment in comparison with other software tools. The proposed IFC Platform is a prototype that aims to interpret and manage IFC data models. The process of this interoperability experiment is illustrated in Figure 2. As depicted, these four test tools were named Software A to

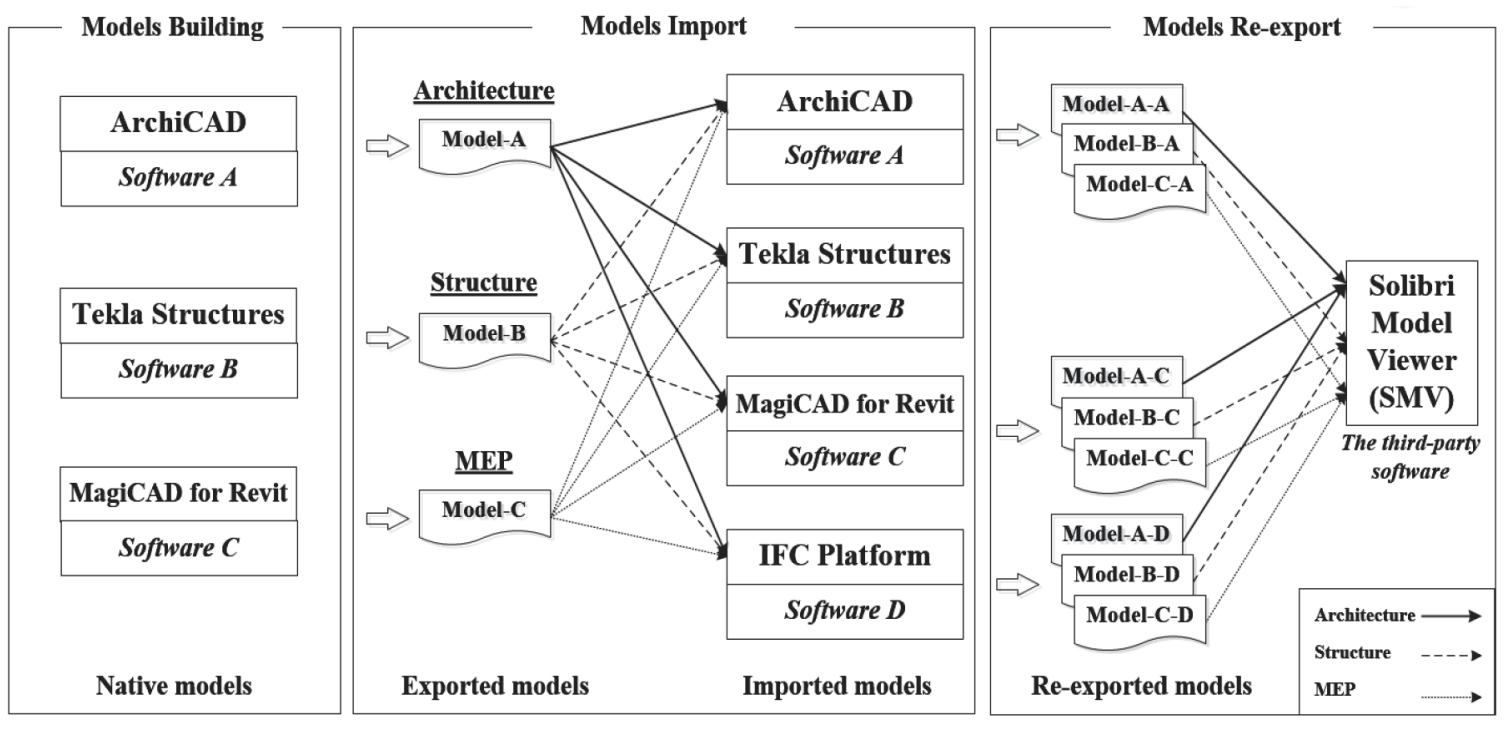

Figure 2. Data interoperability experiment for IFC data exchange between BIM software 
Software D, respectively, and three types of data models (that is, architectural, structural and MEP models) were used to analyze data sharing and exchange between aforementioned software tools:

1. Models Building: Domain-specific software tools (Software A, B, and C) were used to build models of three disciplines to ensure accurate representation, and then exported IFC models within default software's settings for IFC export. These IFC models were named Model-A, Model-B, and Model-C, respectively.

2. Models Import: These exported IFC models were imported into four software tools for the import test, including Software A, B, C, and D. Different kinds of objects from three models were selected to verify the interpretation of IFC models in these software tools.

3. Models Re-export: When importing original IFC files, these software tools converted IFC models to internal models, and then re-exported IFC files without modifications. These re-exported IFC files were imported into a third-party software tool (Solibri Model Viewer (SMV) in this example) for the export test. These models were renamed by adding the software code in the last part of the original model name. For example, Model-A re-exported from Software B was renamed Model-A-B. It is noteworthy that (a) IFC files were imported into Software B as reference models that could not be re-exported, so the re-export test in Software B was not conducted here; (b) in Software C, IFC models were re-exported through the data interface of Revit.

\subsection{Test models and criteria}

In this experiment, a 5-story office building with an area of about $2,400 \mathrm{~m}^{2}$ was selected as the test case. It is a small project, but includes required objects and related attributes. To reflect data sharing and exchange in practice, several typical objects from three disciplines were selected: (a) the wall and window for architecture, (b) the beam and reinforcing bars for structure, and (c) the pipeline and terminal for MEP (see Table 2). Contrary to the IFC certification process that tests "standard objects", test objects used in this experiment include some common simpleshaped objects (e.g., the wall, beam, and pipeline), but also cover those with complex geometries, such as the window, reinforcing bars, and flow terminal. These selected objects are representative in corresponding domains, and other types of objects can be tested in the similar manner. As mentioned above, three models (architecture, structure, and MEP) of this building were built by ArchiCAD 20, Tekla Structures 2017 and MagiCAD 2017, respectively. The models created by these three tools are displayed in Table 2.

Differences between IFC models were firstly discussed at the overall level, such as file sizes and numbers of objects. Different kinds of attributes contained in objects can be mapped into relevant IFC object types and their geometry, properties, and relations (Eastman et al. 2011). Hence, these feature information of objects was chosen as the test criteria, including the type, geometry, property, and relation. In addition, the colour of objects is important for the visual representation of building projects, so the colour

Table 2. Test models for the interoperability experiment

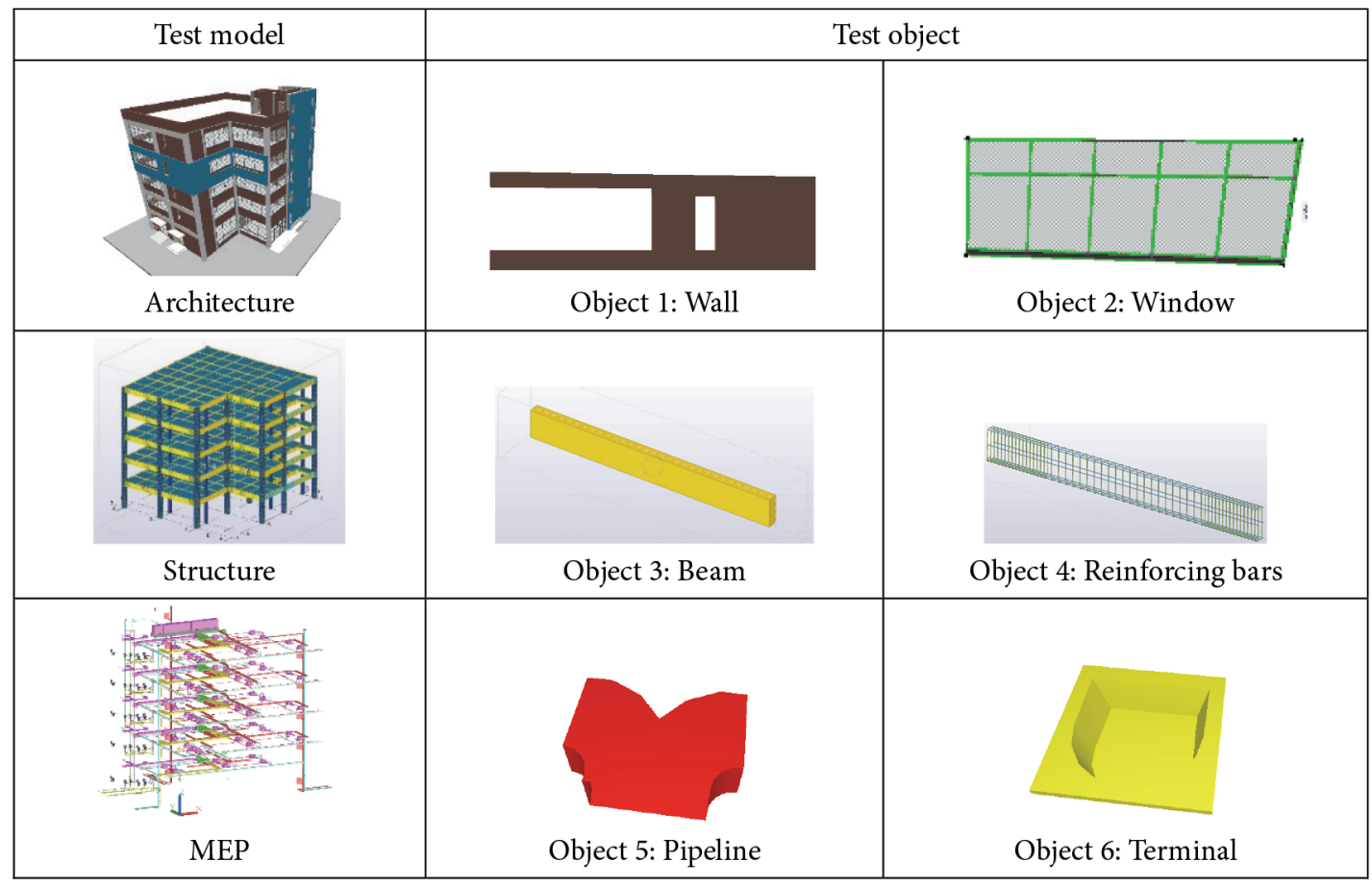


was taken as one of test criteria in this experiment. The visual inspection method was used to view the imported IFC models in four test tools. All re-exported models were imported in SMV for viewing, and the IFC File Analyzer (National Institute of Standards and Technology 2011) was used to automatically analyze the overall information of these models. Further, the causes of interoperability issues would be manually analyzed at the IFC data level.

\section{Results and analysis of data interoperability experiment}

The overall results of imported and re-exported models are presented in Table 3 and Table 4, respectively. In terms of test criteria, the results would be further analyzed by the following groups: overall information of models, and types, geometry, colours, properties, and relations of objects.

\subsection{Overall information of models}

Through statistical analysis by using the IFC File Analyzer, information of all elements in re-exported IFC models are provided in Table 5. (1) For the re-exported architectural models, Model-A-A and Model-A-D were almost the same as Model-A, but the file size of Model-A-C increased $115.9 \%$. Additional 68,330 IFC entities and 1,776 property sets were added in Model-A-C; (2) When Model-B were re-exported from Software A and Software C, there were significant differences in file sizes, IFC entities, and property sets in Model-B-A and Model-B-C. In addition, there was no IfcBeam or IfcReinforcingBar entity in Model-B-C, which had 333 new IfcBuildingElementProxy entities. No significant difference was found in Model-B-D. The results of re-exported MEP models were similar to those of reexported structural models.

Table 5 revealed that even if no modification was made to original models, the file sizes of re-exported models from Software A and Software C could increase. The file size of Model-B-A, for example, dramatically increased $19,388.4 \%$. The cause is that domain-specific software tools have domain knowledge to represent the information in their own disciplines, but may not explicitly interpret specific information from other disciplines. For instance, domain-specific software tools create 3D geometric shapes using parametric modeling methods, but other tools may use nonparametric modeling methods due to the lack of domain knowledge. Taking the geometric representation of reinforcing bars as an example, Model-B had numerous reinforcing bars represented by IfcSweptDiskSolid, a parametric shape representation. Nevertheless, neither Model-B-A nor Model-B-C had IfcSweptDiskSolid entities, as depicted in Table 5. It indicates that neither Software A nor Software C supports this method for shape representation. Instead of using IfcSweptDiskSolid, IfcFacetedBrep with numerous IfcFace entities was used in Model-B-A and Model-B-C. As a result, Model-B-A and Model-B-C had 2,371,856 and 388,112 IfcFace entities, respectively.
Although the method with IfcFace could be used to represent the geometric shape of reinforcing bars, it lost the feature geometric parameters (more details on the geometric shape of reinforcing bars were discussed in Subsection 3.3), but also required much more IFC entities than the method with IfcSweptDiskSolid, resulting in large file sizes. On the other hand, the file sizes of all re-exported models from Software D changed a little. As mentioned above, Software D was developed based on IFC schema. IFC models can be interpreted by software D without any conversion to other data schemas, remaining their original data structures. Only the header section and instance numbers of IFC files may be updated according to default settings.

\subsection{Object types}

As IFC schema provides the GUID to identify objects, test objects can be queried through their GUIDs. The types of test objects in original and re-exported models are documented in Table 6. The issues related to IFC-based object types could be concluded: (1) In Model-B-C, entities for the beam (IfcBeam) and reinforcing bars (IfcReinforcingBar) from Model-B were transformed to IfcBuildingElementProxy; (2) A terminal (IfcFlowTerminal) was lost in Model-C-A; (3) The object type of a terminal in Model$\mathrm{C}$-C changed from IfcFlowTerminal to IfcBuildingElementProxy.

In the first issue, the reinforcing bar was selected as an example for analysis. The reinforcing bar in Model-B was represented as IfcReinforcingBar entity, and IfcBuildingElementProxy entity was used in Model-B-C. The IfcBuildingElementProxy entity is generally used to express objects undefined in IFC schema. Software $\mathrm{C}$ may lack the definition or not support the interpretation of reinforcing bars, resulting in the utilization of IfcBuildingElementProxy entity. Although IfcBuildingElementProxy entity is able to express objects (Lee et al. 2011), this entity is not for domain-specific objects, and it is difficult for software tools to recognize and use. In the second issue, most objects of Model-C-A could be displayed, except for the terminal, as shown in Table 4. The reason for such issue is that as an architectural tool, Software A lacks the required domain knowledge to define specific information in MEP domain. According to the IFC import report, Software A didn't support the geometric representation of this terminal, resulting in its missing. The cause of the third issue was similar to the first one.

\subsection{Geometry of objects}

Table 3 illustrates geometric representations of Model-A, Model-B, and Model-C imported in test tools. Through visual inspection, geometric representations of Model-A and Model-B in four tools were the same as the original models. Geometric representations of Model-C in Software $\mathrm{B}, \mathrm{C}$, and $\mathrm{D}$ were accurate, but the terminal was missing in Software A. On the other hand, geometric representations of re-exported models in SMV are present- 


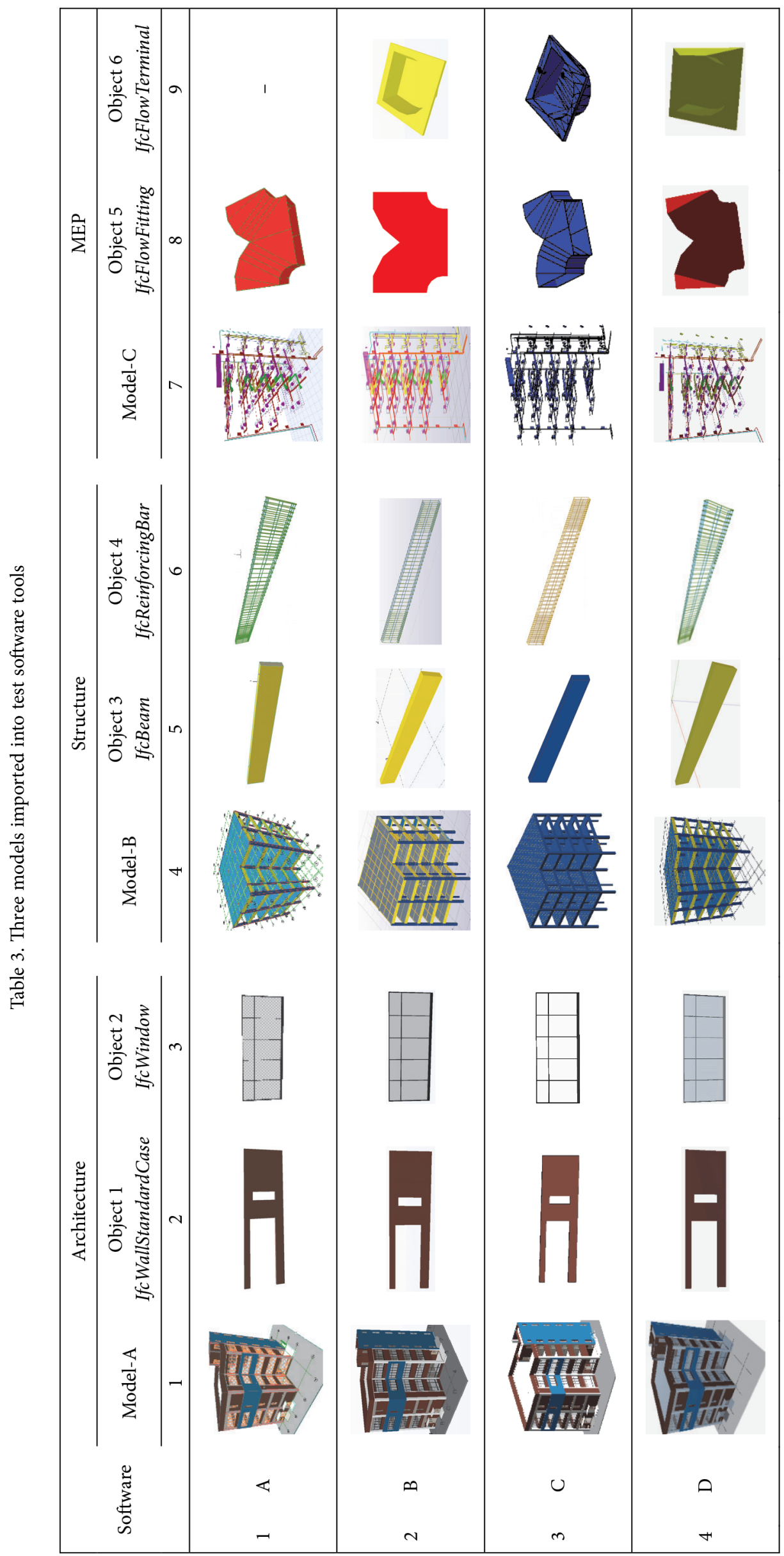




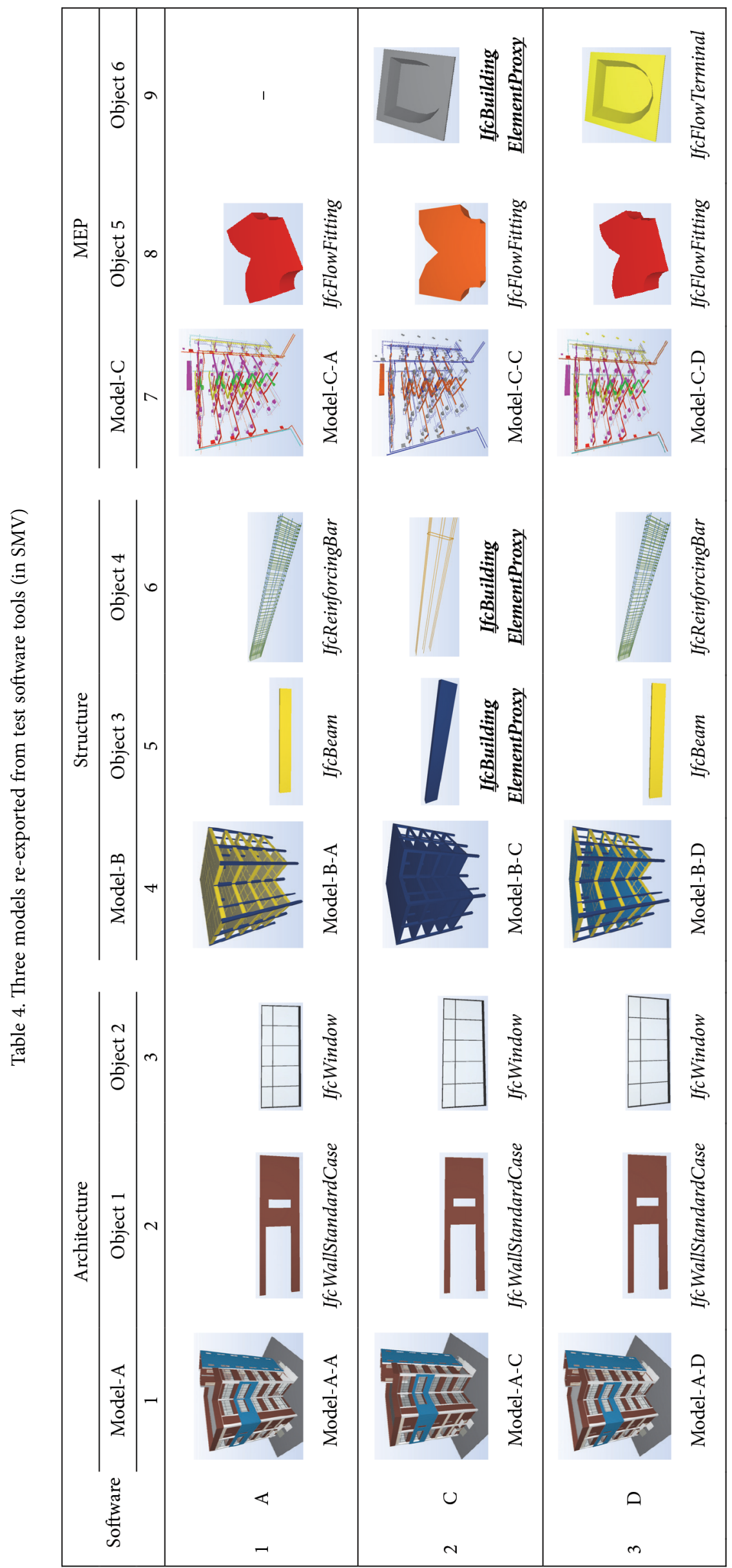


Table 5. Re-exported models from Software A, C, and D

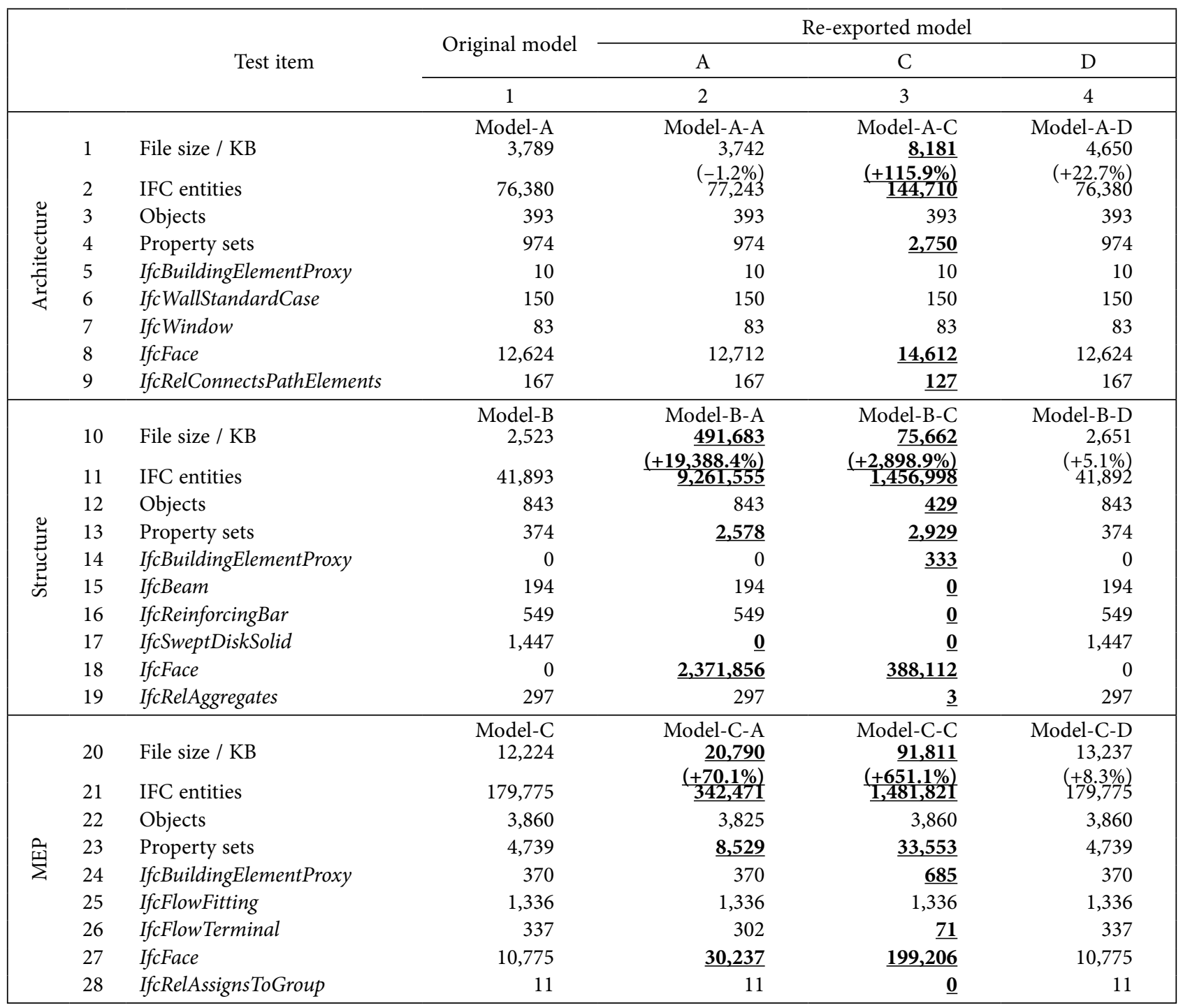

Note: In this paper, significant differences were marked as bold and underlined text.

ed in Table 4. Two types of misinterpretations could be found: (1) Misrepresentation: In Model-B-C, only a part of reinforcing bars were displayed. (2) Missing: A terminal was lost in Model-C-A.

The IFC entities used for the geometry of test objects are detailed in Table 6. Although IFC object entities generated from diverse software tools are consistent, their geometric representations may differ from the original. For example, the IFC object entity for the reinforcing bars in Model-B-A was IfcReinforcingBar, the same as the original one, but the geometry represented by IfcSweptDiskSolid was converted to the representation with IfcFacetedBrep in Model-B-A. Both IfcSweptDiskSolid and IfcFacetedBrep can be used to express the geometry of reinforcing bars, but the method using IfcFacetedBrep is more complex. Through analyzing Model-B and Model-B-A, IFC entities for geometric representation of the reinforcing bars are illustrated in Figure 3. In Model-B, one IfcSweptDiskSolid entity had 13 IfcCompositeCurveSegment entities, each of which referred to one IfcTrimmedCurve entity. Nevertheless, each IfcFacetedBrep entity in Model-B-A included one IfcClosedShell with 294 IfcFace entities. As seen in Table 5, no If $c$ Face entity was found in Model-B, and Model-B-A generated 2,371,856 new IfCFace entities. This resulted in a distinct difference in the file size between Model-B and Model-B-A. In Model-B-C, the geometric representation of the reinforcing bars was also represented by IfcFacetedBrep, but only 388,112 IfcFace entities were newly generated, as shown in Table 5. This was why only a part of reinforcing bars were displayed in Model-B-C.

For the loss of the terminal in Software A, according to the import report, some polygons represented by IfcFace in this terminal were not perpendicular to the normal vector, and this representation method was not supported by Software A. Due to the misinterpretation during the import process, this terminal was not re-exported from Software A, resulting in its loss in Model-C-A. 
Table 6. IFC object entities and their geometric representations in re-exported models

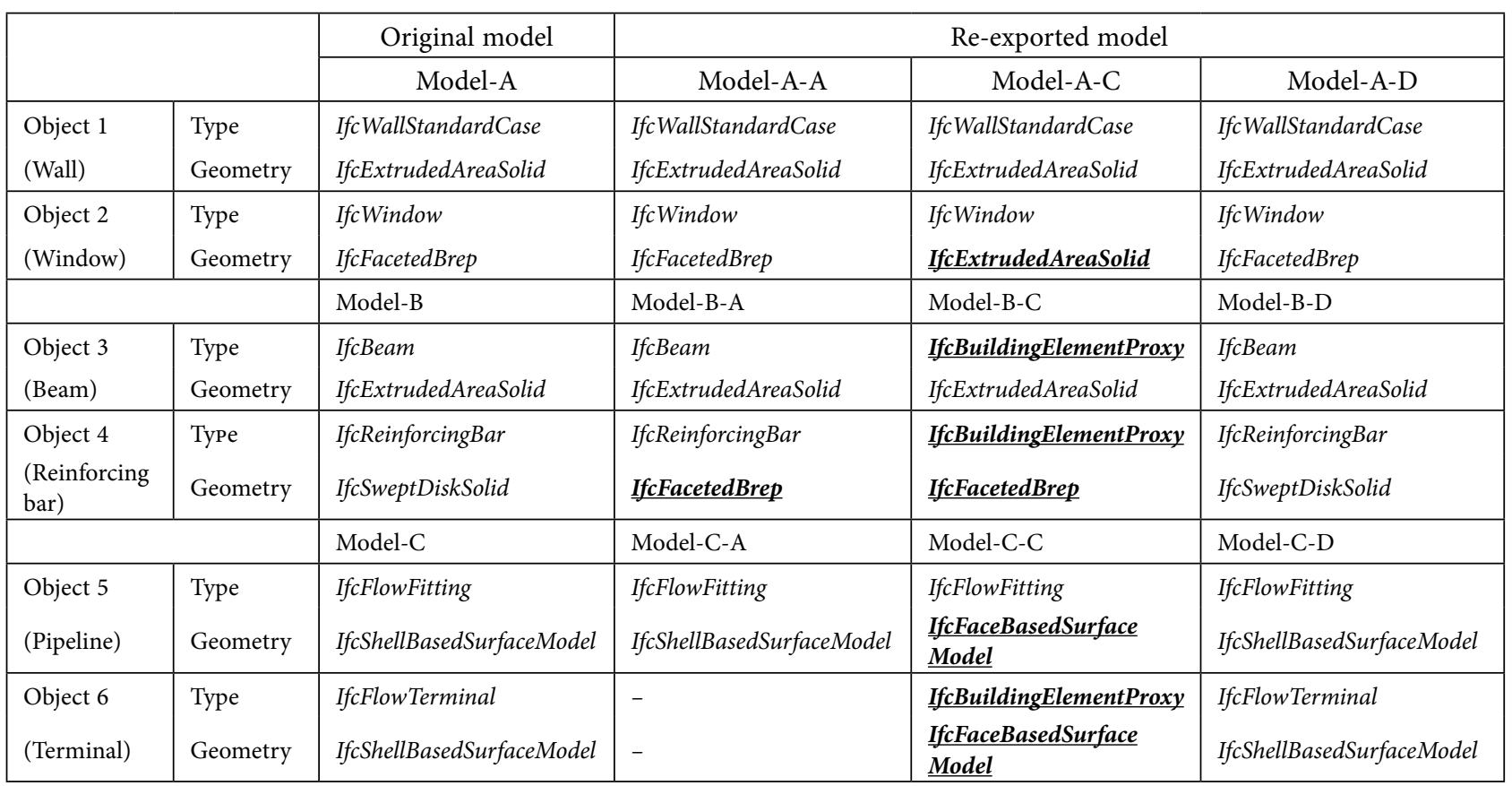

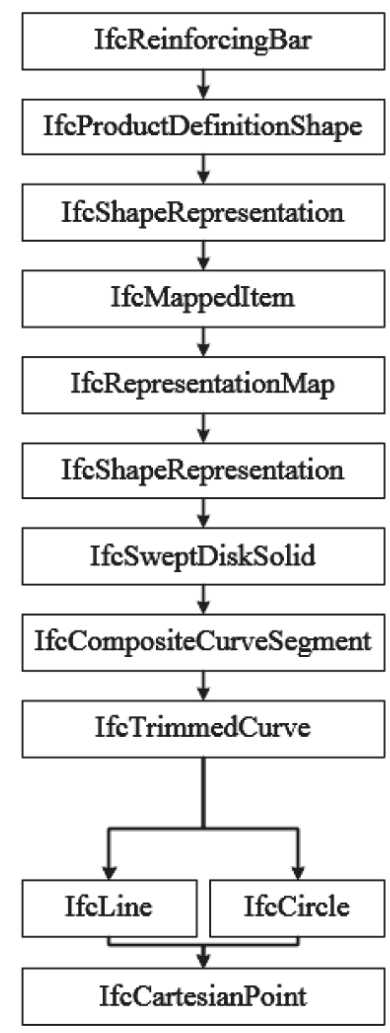

Object 4 in the Model-B

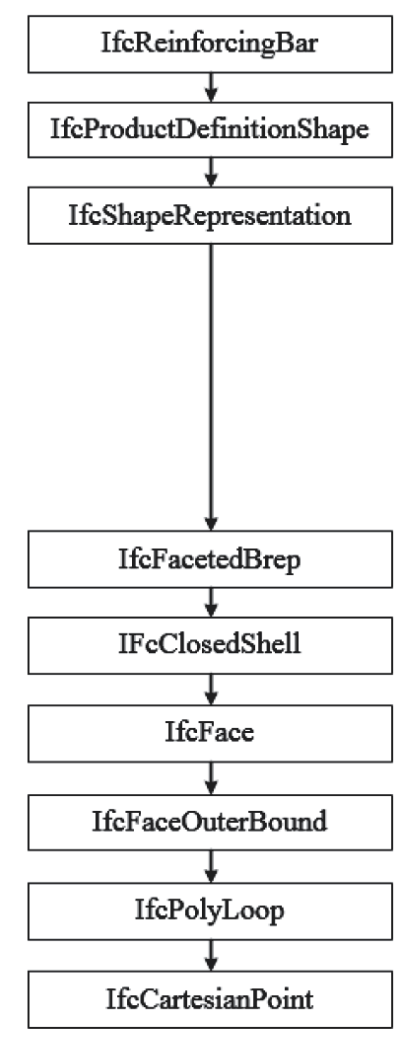

Object 4 in Model-B-A
Figure 3. Geometric representation of the reinforcing bars in different IFC models

\subsection{Colours of objects}

When building test models, modelers defined diverse material data for different objects, and the default colours in reference to material data were retained. In Table 3, all test models and their test objects imported into Software B and Software D were displayed with correct colours; except for the missing terminal, colours of other objects in test models were accurate in Software A. When Model-B was imported into Software $C$, the yellow-colored beam turned to blue, and the reinforcing bars became yellow from green; all objects from Model-C changed to blue in software C.

The re-exported models were imported into SMV for the visual check, as shown in Table 4. The associated results were: (1) Objects from three re-exported architectural models had the same colours as Model-A. (2) The colours of the beam and reinforcing bars in Model-B-A were accurate, but the slabs changed from blue-green to yellow. Within Model-B-C, the green-colored reinforcing bars became yellow, and blue for other objects. (3) Except for the missing terminal, other objects in Model-C-A had correct colours. Significant differences in colours were found in Model-C-C. For example, the pipeline became orange from red, and the terminal changed to gray from yellow.

IFC schema provides multiple ways to represent colours. The colour representation methods of test objects are summarized in Table 7 . Software C could correctly interpret the colours of the wall and window from Model-A, but display incorrect colours of objects from Model-B and Model-C. It indicates that Software C may not support the third method to the fifth method in Table 7.

In IFC schema, colour information is generally defined by $(\mathrm{R}, \mathrm{G}, \mathrm{B})$ values in $I f_{c}$ ColourRgb entity. There are various methods to define the relations between objects and colours. Examples include IfcMaterial and IfcMappedItem, that is, the first and fifth methods in Table 7 , respectively. Figure 4 illustrates the relations between objects and colours using these two methods. It demonstrates that the 
Table 7. IFC-based colour representation methods

\begin{tabular}{|c|c|c|c|c|c|}
\hline & 1 & 2 & 3 & 4 & 5 \\
\hline & IfcObject & IfcObject & IfcObject & IfcObject & IfcObject \\
\hline & $\uparrow$ & $\frac{1}{b}$ & 南 & 古 & 南 \\
\hline & IfcRelAssociatesMaterial & IfcShapeRepresentation & IfcShapeRepresentation & IfcShapeRepresentation & IfcShapeRepresentation \\
\hline & $\downarrow$ & $\downarrow$ & $\downarrow$ & $\downarrow$ & $\downarrow$ \\
\hline & IfcMaterial & IfcFacetedBrep & IfcExtrudedAreaSolid & IfcSweptDiskSolid & IfcMappedItem \\
\hline & $\nabla$ & $\Delta$ & $\uparrow$ & $\uparrow$ & $\uparrow$ \\
\hline & IfcStyledItem & IfcStyledItem & IfcStyledItem & IfcStyledItem & IfcStyledItem \\
\hline & $\nabla$ & $\frac{1}{\nabla}$ & 光 & $\vec{\nabla}$ & $\dot{\nabla}$ \\
\hline & IfcColourRGB & IfcColourRGB & IfeColourRGB & IfeColourRGB & IfcColourRGB \\
\hline Model-A & Wall & Window & - & - & - \\
\hline Model-B & - & - & Beam & Reinforcing bars & - \\
\hline & & & & & Pipeline \& \\
\hline Model-C & - & - & - & - & Terminal \\
\hline
\end{tabular}

Note: "A $\rightarrow$ B" means that A refers to B directly; "A $\rightarrow$ B" means that at least one referencing element exists between A and B, e.g., "

$\mathrm{A} \rightarrow \mathrm{C} \rightarrow \mathrm{B}$ ".

same colour information can be represented by a variety of methods in IFC schema. As each software tool is able to support some of these methods, rather than all ones, the software tool may not interpret colour information that is represented through other methods. Multiple methods for the same information significantly add the complexity of interpretation for software tools.

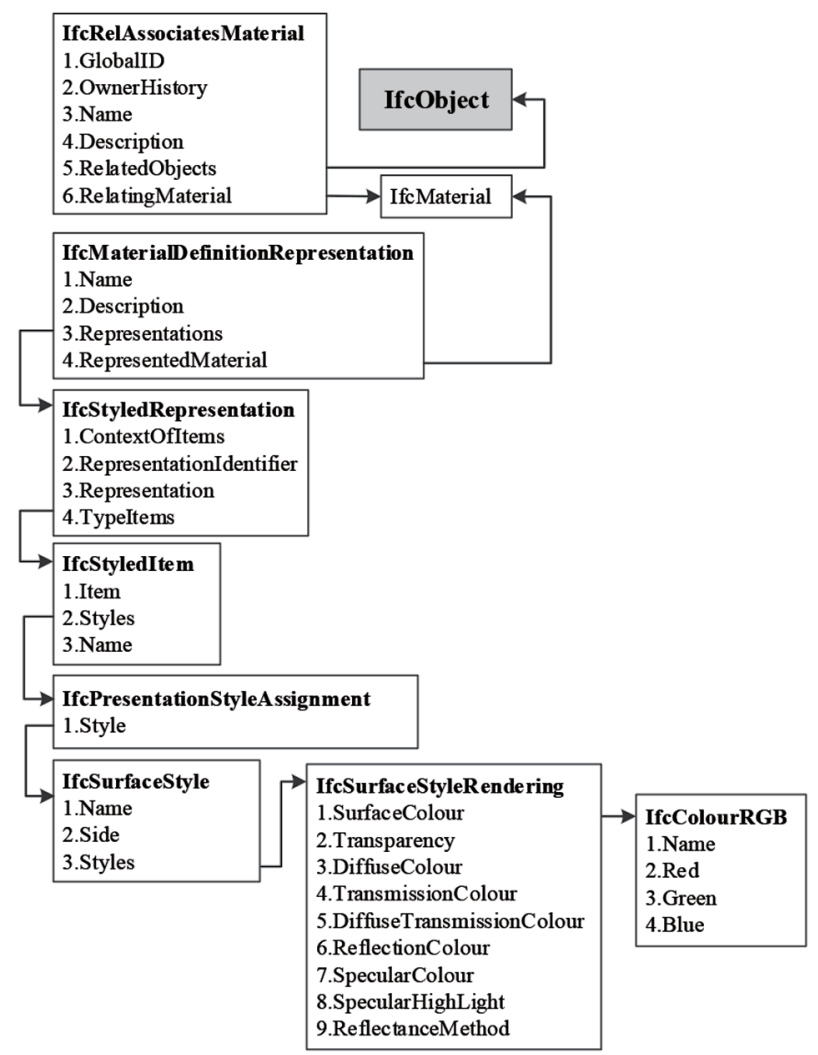

(a) IfcMaterial-based method

\subsection{Properties of objects}

To analyze the interoperability issue in the property, different types of properties were manually added in test objects, as listed in Table 8.

In import test, (1) all properties of the wall and window in Software A, C, and D were consistent with those in Model-A, but the glazing area fraction of the window

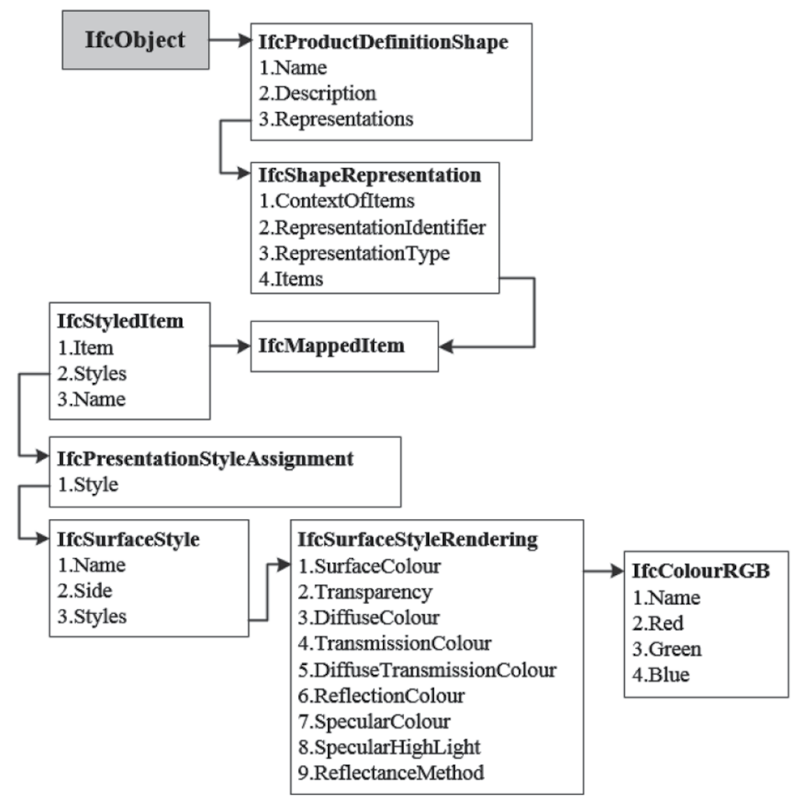

(b) IfcMappedItem-based method

Figure 4. Examples of different methods for colour representation using IFC schema 


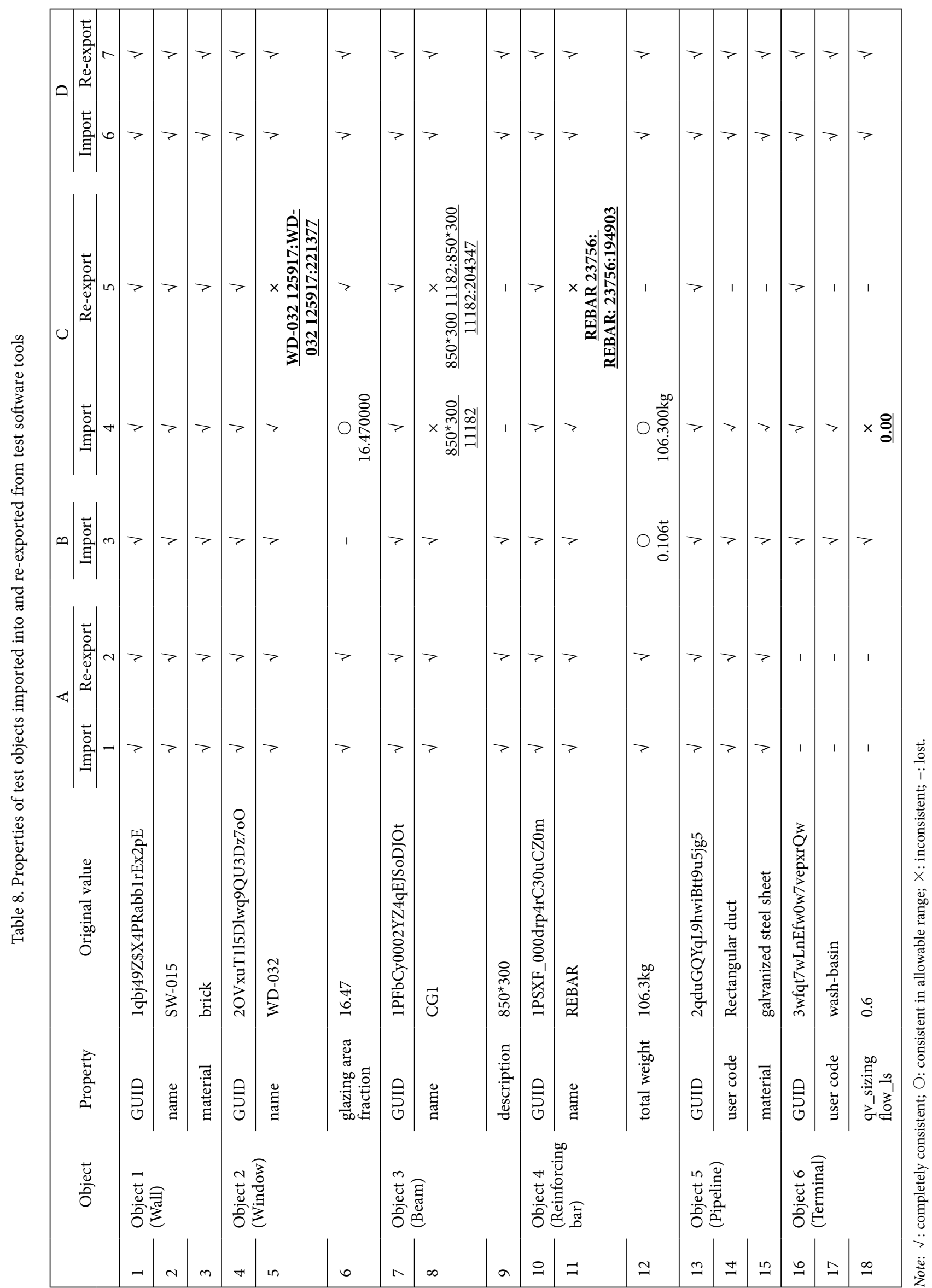


was lost in Software B. (2) The beam and reinforcing bars interpreted by Software A and Software D had correct properties. Rather than the used unit of a kilogram $(\mathrm{kg})$ in the original model, the unit of a ton $(t)$ was used for the total weight of reinforcing bars in Software B, and its precision (106.300) in Software C was different from the original one (106.3). In addition, the beam name in Software $\mathrm{C}$ was wrong. (3) Software A showed correct properties of the pipeline, but lost the terminal. Both Software B and Software D could correctly interpret properties of the pipeline and terminal. Properties of the pipeline were correct in Software C, but the property value of "qv_sizing flow_ls" of the terminal was wrong.

In re-export test, (1) properties in both Model-A-A and Model-A-D did not differ from those in Model-A. In Model-A-C, the window name was incorrect. (2) In Model-B-A and Model-B-D, no change was found in properties of the beam and reinforcing bars. In Model-B-C, their names were misrepresented, and the total weight of the reinforcing bars was lost. (3) Properties of the pipeline and terminal in Model-C-D were valid. Except for the missing terminal, properties of the pipeline in Model-C-A were correct. Several properties in Model-C-C was lost, such as the material of the pipeline and user code of the terminal.

In conclusion, three types of issues in object properties were as follows: (1) Loss of object properties. For example, the glazing area fraction of the window was lost in Software B, as well as the user code of the terminal in Software $\mathrm{C}$. Through analyzing corresponding IFC entities, these properties were defined by IfcPropertySingleValue entities. It indicated that Software B and Software C did not accurately interpret all properties defined by IfcPropertySingleValue. (2) Inconsistent property values. This issue mainly occurred in the name, e.g., the beam name. The name is an attribute of IfcRoot, and all building elements defined in IFC schema inherit this attribute. These results implied a misrepresentation of the element name. (3) Differences in numerical precision. While the total weight of the reinforcing bars in Model-B was $106.3 \mathrm{~kg}$, the corresponding values in Software B and Software C were $0.106 \mathrm{t}$ and $106.300 \mathrm{~kg}$, respectively. In the allowable range, these property values were identical. The precision difference was caused by the default unit and numerical precision in different software tools.

\subsection{Relations between objects}

Relations between objects in a building are crucial for business tasks, such as connections for structural analysis, and system relations for facility management. In this experiment, several relations between objects were designed to test how software tools interpreted relations. In ModelA, IfcRelConnectsPathElements was used to represent the connection relation between walls; in Model-B, the aggregation relation between concrete objects and reinforcing bars was referred by IfcRelAggregates; in Model-C, some objects were assigned to a system by IfcRelAssignsToGroup. The numbers of the aforementioned entities were provided in Table 5. (1) In architectural models, the numbers of IfcRelConnectsPathElements entities in Model-A-A and Model-A-D were 167, but only 127 ones could be counted in Model-A-C. (2) In structural models, Model-B-C had only 3 IfcRelAggregates entities, while the numbers of IfcRelAggregates entities in Model-B-A and Model-B-D were 297, as the same as Model-B. (3) In MEP models, both Model-C-A and Model-C-D had 11 IfcRelAssignsToGroup entities, and no one was found in Model-C-C. The results showed that some relations between objects could not be re-exported from test tools. The relation between the beam (Object 3) and reinforcing bars (Object 4), for example, was analyzed in the following section.

Figure 5 illustrates the relations between the beam and reinforcing bars from different models. In Model-B, IfcRelAggregates specified that the beam and reinforcing bars belonged to an element assembly IfcElementAssem$b l y$, as shown in Figure 5(a). Even though the beam and reinforcing bars could be displayed in Model-B-C, the IfcRelAggregates entity between them was lost. This result reveals that Software $\mathrm{C}$ may not support the interpretation of this relation. For further analysis, a test that there was no assembly relation between the beam and reinforcing bars was conducted, and this new model was called Model- $\mathrm{B}_{\text {new. }}$ In this case, both the beam and reinforcing bars were contained in IfcBuildingStorey by using IfcRelContainedInSpatialStructure entity, as shown in Figure 5(b). Although these two objects in Model- $B_{\text {new }}$ were correctly interpreted by Software C, the assembly relation between them was lost.

Table 9. Average scores to evaluate the interoperability for test objects

\begin{tabular}{|llcccccc|}
\hline & \multicolumn{1}{c}{ Object } & Type & Geometry & Colour & Property & Relation & Total average \\
\hline Architecture & Wall & 1.000 & 1.000 & 1.000 & 1.000 & 0.833 & 0.967 \\
& Window & 1.000 & 0.929 & 1.000 & 0.857 & - & 0.946 \\
\multirow{2}{*}{ Structure } & Beam & 0.667 & 1.000 & 0.714 & 0.857 & 0.667 & 0.781 \\
& Reinforcing bars & 0.667 & 0.857 & 0.714 & 0.929 & 0.667 & 0.767 \\
MEP & Pipeline & 1.000 & 0.929 & 0.714 & 0.929 & 0.667 & 0.848 \\
& Terminal & 0.333 & 0.643 & 0.429 & 0.571 & 0.333 & 0.462 \\
Total average & & 0.778 & 0.893 & 0.762 & 0.857 & 0.633 & 0.790 \\
\hline
\end{tabular}




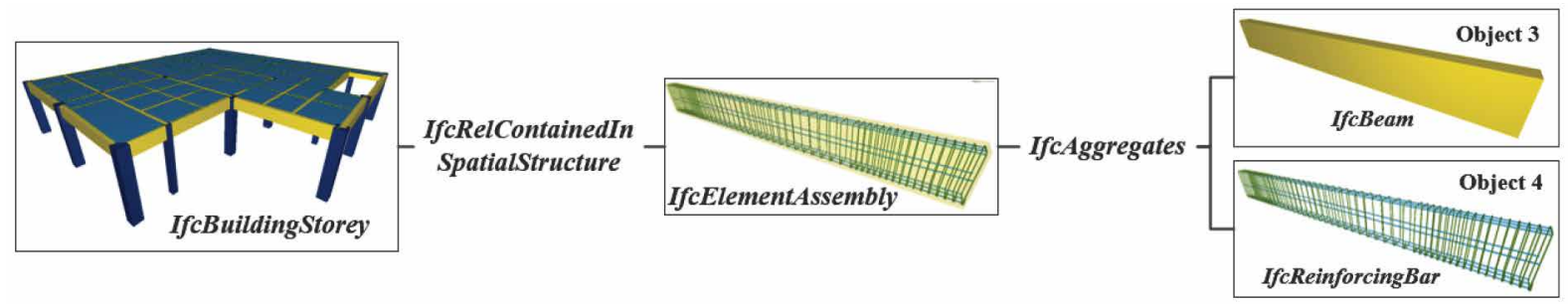

(a) Beam and reinforcing bars within IfcElementAssembly in Model-B

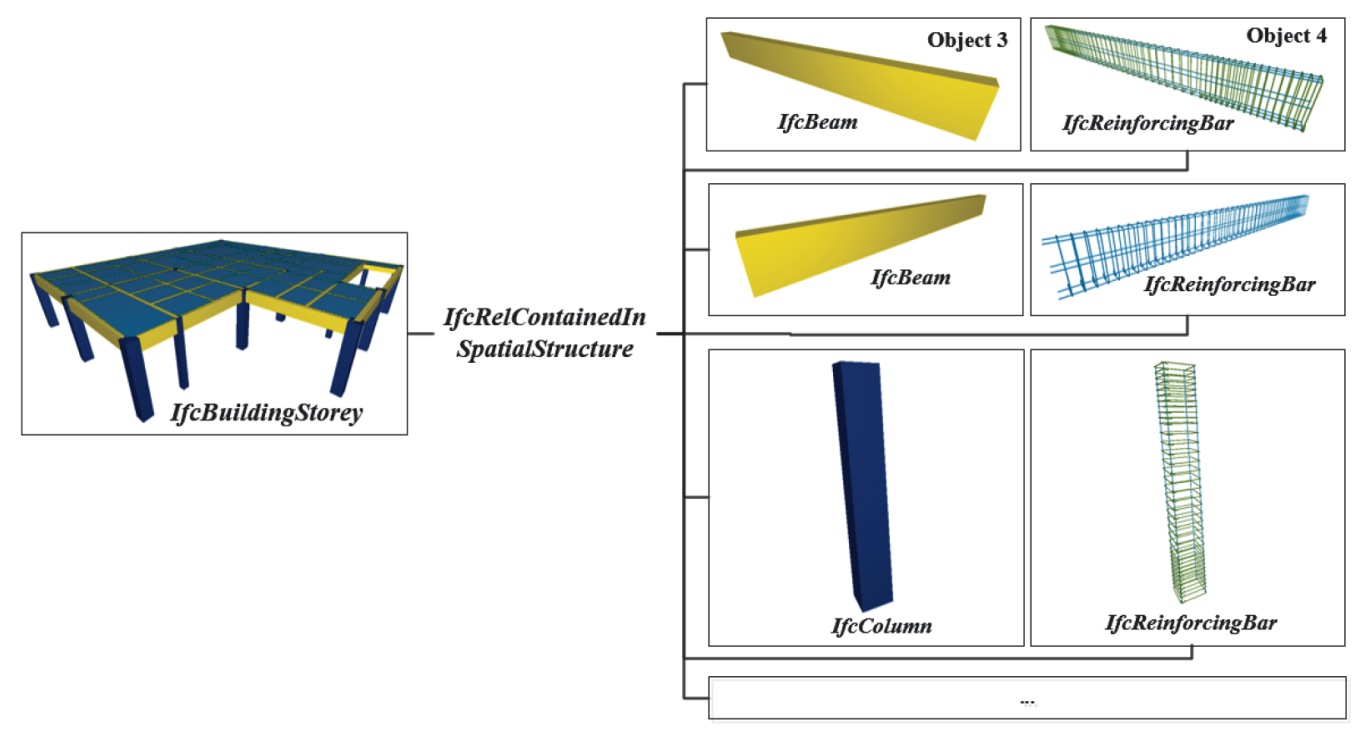

(b) Beam and reinforcing bars without IfcElementAssembly in Model- $\mathrm{B}_{\text {new }}$

Figure 5. Relations between the beam and reinforcing bars in different models

\subsection{Discussion}

This study adopted the scoring mechanism in Muller et al. (2017) to evaluate the interoperability in terms of test criteria. Similar to the Likert scale, three scores were designed to evaluate the accuracy of exchanging data: 1 for completely correct, 0.5 for partially correct, and 0 for completely incorrect. According to the results from the import and re-export tests, Table 9 presents the average scores for each test object in terms of test criteria.

According to total average scores in test criteria, the geometry and property perform the best among existing criteria, and the most serious issue is the relation information, which has a lowest average score. Based on these results, software developers can devote to improving the interpretation of corresponding object attributes, especially in the relation information. On the other hand, the score for the terminal is the lowest among test objects, because it is lost in Software A, resulting in lower scores in each criterion. Among other test objects, the score for the wall is the highest, and the reinforcing bar is the lowest. It indicates that IFC interfaces of software tools should provide better support in the interpretation of complex-shaped objects.

\section{Discussion on methods for data interoperability}

\subsection{Current method for data interoperability}

The current method for data interoperability between heterogeneous software tools is bidirectional, as shown in Figure 6(a). It is assumed that a designer uses Software A to build a data model (called Set $A$ ), and exports this model as IFC format (called Set $A^{\prime}$ ). According to the requirements of business tasks, Software B imports Set $A^{\prime}$, which will be mapped to the internal data schema of Software B. Similarly, Set $B$ is assumed to be a set of information expressed by the internal data schema of Software B. Ideally, all elements in Set $A^{\prime}$ can be mapped to relevant elements in Set $B$, so that $\forall a \in A^{\prime} \rightarrow a \in B$, as shown in Figure 6(b). The results from Section 3 indicate that interoperability issues do exist during data sharing and exchange between heterogeneous software tools. It means that one software tool can hardly support all information from other disciplines. As shown in Figure 6(c), while an element $a_{i}$ in Set $A^{\prime}$ belongs to Set $B$ (that is, $\left.a_{i} \in\left(A^{\prime} \cap B\right) \subset B\right)$, there are other elements which don't 


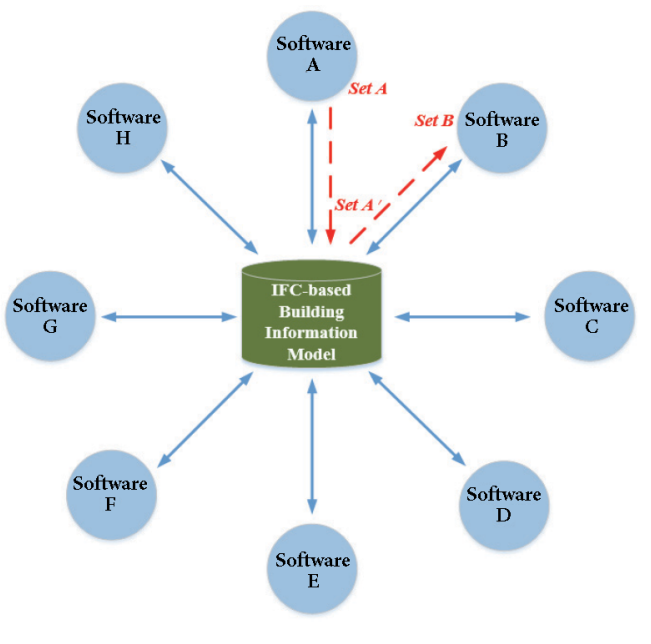

(a) Bidirectional interoperability

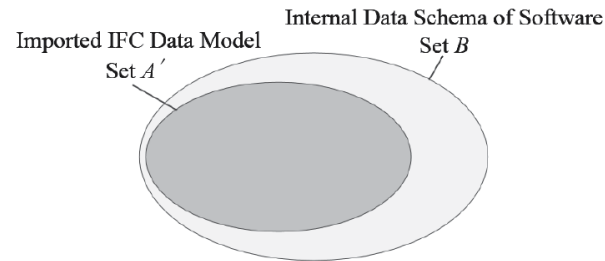

(b) Ideal case

Internal Data Schema of Software

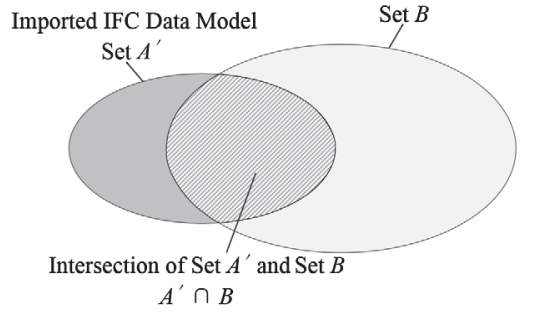

(c) Current case

Figure 6. Data interoperability in a bidirectional way

belong to Set $B$, e.g., $a_{j} \in A^{\prime} \wedge a_{j} \notin B$. If Software $A$ and Software $B$ belong to different disciplines, more elements in Set $A^{\prime}$ will not belong to Set $B$ because of semantic differences. Mathematical notations in this paper are based on the Mathematical Logic and Set Theory (Oleary 2015).

A software tool can hardly support all information in the AEC/FM industry (Smith, Tardiff 2009). The information supported by a software tool is usually a subset of all information of building projects. When a tool imports a model which is created by itself or belongs to the same discipline, this imported model can be interpreted well. Subsequently, the re-exported model is also highly consistent with the original one. In Figure 7(a), elements $a_{i}(i=1,2$, $3, \ldots, n)$ included in Set $A^{\prime}$ can be mapped to elements $b_{i}(i=1,2,3, \ldots, n)$ in Set $B$ through a function $f$, that is, $f\left(a_{i}\right)=b_{i}(i=1,2,3, \ldots, n)$. Consequently, there is an equivalence relation between the re-exported model (called
Set $\left.\left(A^{\prime}-B^{\prime}\right)\right)$ and Set $A^{\prime}$. If the tool imports a model which is created by a third-party tool, a part of model data is easily misrepresented and/or lost. As shown in Figure 7(b), these mappings between the internal data model and the IFC model can be classified into three cases:

Case 1: For elements $a_{i}(i=1,2,3, \ldots, n)$, similar to Figure 7(a), elements $a_{i}$ can be mapped to elements $b_{i}$ in Set $B$, that is, $f\left(a_{i}\right)=b_{i}(i=1,2,3, \ldots, n)$. This part of Set $\left(A^{\prime}-B^{\prime}\right)$, including elements $b_{i}$, is consistent with relevant elements in Set $A^{\prime}$.

Case 2: For elements $a_{n+j}(j=1,2,3, \ldots, m)$, there are no elements in Set $B$ mapping elements $a_{n+j}$ by one to one. These elements $a_{n+j}$ can be mapped to one particular element (e.g., the element $b_{0}$ ) through a specific function. In other words, there is a many-to-one mapping relation between elements $a_{n+j}$ and element $b_{0}$, that is, $\exists g\left(a_{n+j}\right)=$ $b_{0}(j=1,2,3, \ldots, m)$. Although the element $b_{0}$ is different

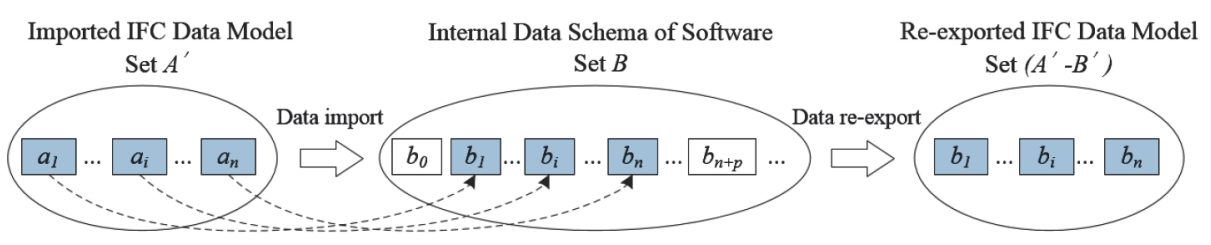

(a) Data import and re-export in the same discipline

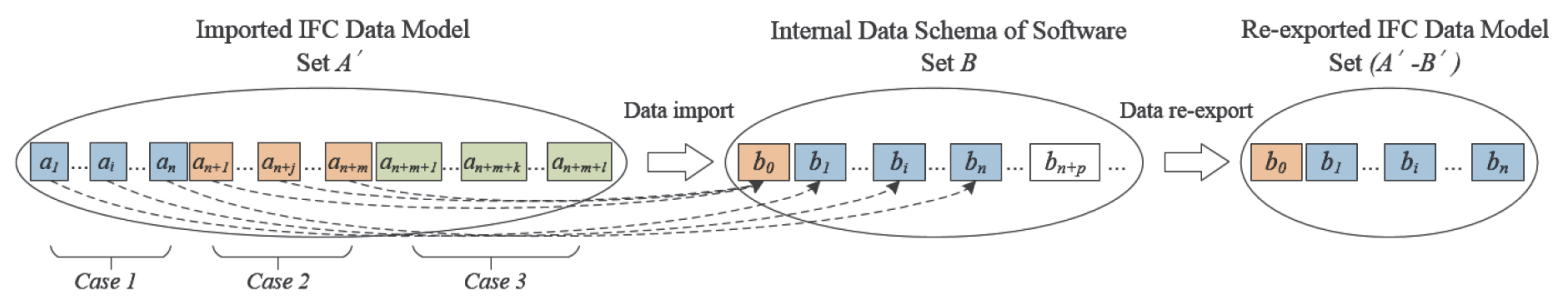

(b) Data import and re-export in different disciplines

Figure 7. Discussion on mappings between internal models of software and IFC data models 
from elements $a_{n+j}$, it can be used to express information represented by $a_{n+j}$ through a function $g$. In IFC schema, the IfcBuildingElementProxy entity is an example for such a purpose, which can be used to represent various IFC object entities. Noted that not all software tools make elements $a_{n+j}$ map to the element $b_{0}$ due to diverse mapping mechanisms, resulting in various mappings.

Case 3: For the rest of elements $a_{n+m+k}(k=1,2,3, \ldots$, $l$ ) in Set $A^{\prime}$, there is no element in Set $B$ mapping these elements because of different disciplines, even the element $b_{0}$. In this case, due to the lack of elements mapping to elements $a_{n+m+k}$, the information represented by elements $a_{n+m+k}$ will be lost in Set $\left(A^{\prime}-B^{\prime}\right)$. As a result, Set $\left(A^{\prime}-B^{\prime}\right)$ has a low accuracy.

In conclusion, during data sharing and exchange between heterogeneous software tools, if the bidirectional data interoperability is used without additional improvement on exchanging data, interoperability issues will likely arise: (1) When importing model data undefined in the internal data schema of software, software tools may lose model data, or map them into other data. Due to diverse mapping mechanisms, it is more prone to various interpretations of the same model data; (2) When software tools export objects with diverse attributes, such as geometry, properties, and relations, methods to define the same attribute may vary depending on software tools, resulting in different representations. According to the existing bidirectional data sharing and exchange, it is recommended to propose a new method to achieve effective data interoperability between heterogeneous BIM software.

\subsection{A suggested method for data interoperability}

When a domain-specific software tool exports its own model as IFC format, both exported and original models are very close in information representation because of semantic compatibility. However, diverse disciplines are involved in the building project. Results in this experiment demonstrate that using one domain-specific software tool for data exchange between multiple disciplines is prone to interoperability issues. In this experiment, the prototype IFC Platform (Software D) showed a good performance of the interpretation, and relevant results demonstrated the feasibility of an IFC-based BIM platform for data interoperability in practice. Hence, a common BIM platform which fully supports IFC schema is suggested to integrate model data from multiple disciplines, as shown in Figure 8(a). Users select domain-specific software tools to build models and export IFC models. Subsequently, these models are integrated into the IFC-based BIM platform.

Due to diverse disciplines (such as architecture, structure, and MEP) in the AEC/FM industry, the common BIM platform is expected to interpret model data from various disciplines. For this purpose, data dictionaries of diverse disciplines were established in the proposed IFC Platform for mapping plenty of model data. As shown in Figure $8(\mathrm{~b})$, Set $Z^{\prime}$ is assumed to be a total information set in the IFC Platform, which includes different data dictionaries. Dictionary 1, 2, and 3, for example, are used for representing architectural, structural and MEP models, respectively. It is assumed that both Set $A^{\prime}$ and Set $B^{\prime}$ belong to the information sets of architectural models. Hence, Dictionary 1 can cover elements in Set $A^{\prime}$ and Set $B^{\prime}$. Any elements in Set $A^{\prime}$ or Set $B^{\prime}$ belong to Set $Z^{\prime}$, that is, $\forall a \forall b\left[A^{\prime}, B^{\prime} \subset\right.$ Dictionary $\left.1 \wedge a \in A^{\prime} \wedge b \in B^{\prime} \rightarrow a, b \in Z^{\prime}\right]$. A common BIM platform with enough such dictionaries can better interpret models from various disciplines.

To date, IFC schema has defined a great deal of information for diverse disciplines, such as architecture, structure, mechanical, electrical and plumbing. Through integrating corresponding information in IFC sche$\mathrm{ma}$, data dictionaries could be formed in the proposed

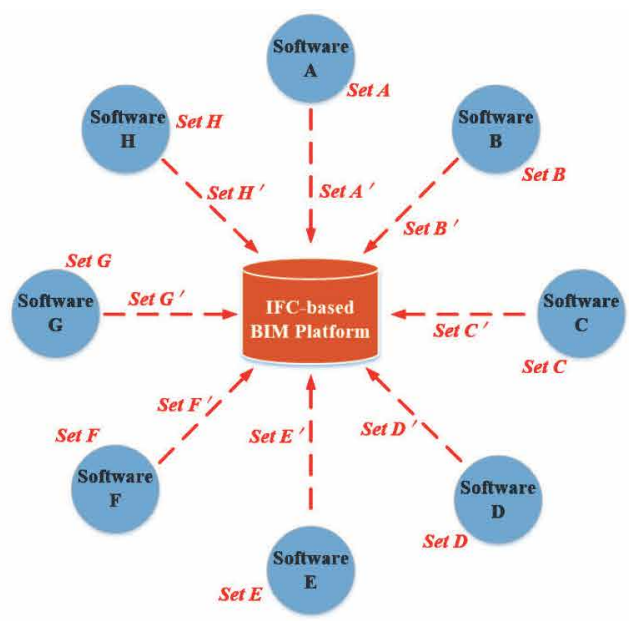

(a) Data interoperability between different software using IFC-based BIM platform

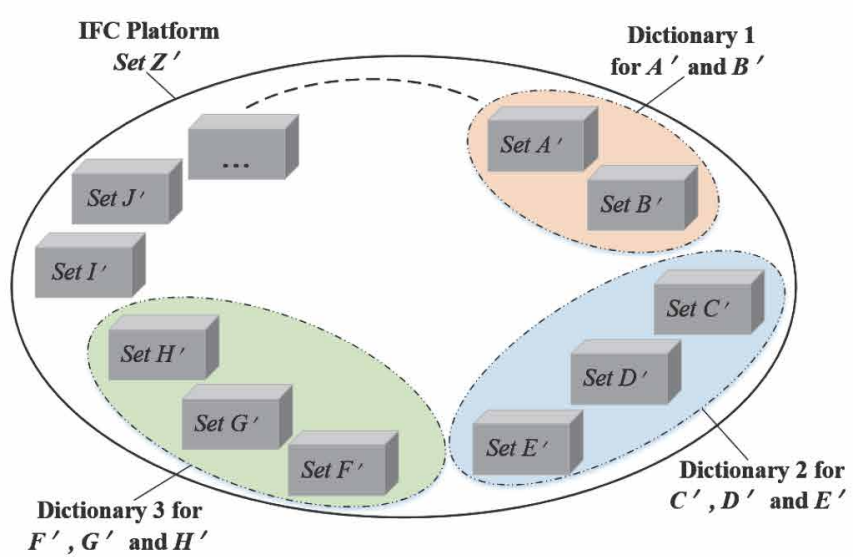

(b) Dictionaries of different disciplines for interpreting IFC data models

Figure 8. Suggested method for data interoperability using IFC-based BIM platform 
platform. Furthermore, to effectively process data models, an IFC-based dataset was established in the IFC Platform. This dataset has various information units for storing different kinds of object information in a standard way, such as the name, type, geometry, property, material, colour, and relation. When importing an IFC file, the proposed platform firstly interprets model data according to the inheritance and referencing relations between IFC instances, and then converts the data to relevant information in dictionaries. A lot of building models created by different software tools (such as ArchiCAD, Tekla Structures, Revit, and Allplan) have been used to test the validity of the proposed IFC Platform, and these tests presented satisfactory results, similar to this interoperability experiment. Due to the length limitation of the paper, this paper focuses primarily on the interoperability experiment, and the methods to establish data dictionaries and associated algorithms for interpreting diverse IFC data are to be described in detail in a separate paper (under preparation). The current IFC Platform is not yet available to support all domains in the AEC/FM industry. IFC schema is being developed to cover more domains, e.g., an extension of the infrastructure domain in IFC5. As the development of IFC schema, the proposed platform is promising to better support information in the AEC/FM industry.

In addition, IFC data models exported from software tools may need to be imported into other software tools for their business tasks. For a correct interpretation, besides improving IFC data interfaces by software developers, the next research work will focus on how to import re-exported IFC models to software tools without data loss or misrepresentation.

\section{Conclusions}

As BIM software tools have been widely used in the AEC/ FM industry, interoperability issues are becoming increasingly prominent. In this paper, a practical project was used to test currently bidirectional data interoperability. Compared to previous tests within one or two domains, this interoperability experiment was designed to test models from architectural, structural and MEP domains. Typical objects in each domain were selected as test objects, which were not limited to "standard objects", but also included domain-specific objects with complex shapes. Further, designated test criteria, including the types, geometry, colours, properties, and relations, covered feature information of objects.

The results demonstrate that interoperability issues commonly arise, such as the increasing file-size, inconsistent object types, geometric misrepresentation, different colours, loss of properties and relations. Through a discussion, it is found that complex-shaped objects (e.g., the terminal and reinforcing bars) present more interoperability issues, and the biggest issue lies with the relation between objects from the view of test criteria. For such interoperability issues, the causes can be concluded as follows:
- Interoperability issues such as data loss and misrepresentation do exist, when software tools import IFC models created by other software tools. This cause lies in semantic differences. The domain-specific software tool can correctly represent information from its own domain. Information from other domains, however, may be lost or misrepresented by software due to the lack of related knowledge in the internal data schema, such as object type and geometric representation.

- When different software tools export the same information of an object, such as geometry, properties, and relations, different IFC entities may be used to define this information, leading to diverse representations. This reason for such difference is the multiple mappings between internal data schemas of software tools and IFC schema.

- When software tools re-export data models created by other software tools, the increase in physical file sizes, IFC entities, etc. can be found. The cause is that software tools prefer to use general methods to represent information undefined in internal data schemas, which will add more IFC data, e.g., nonparametric geometric representation for the complex shape.

Furthermore, the causes of interoperability issues in each characteristic have been further analyzed within the IFC data perspective. It provides users and software developers with a guide on how to improve data interoperability. Even though interoperability issues do exist during IFC-based data sharing and exchange, it cannot be concluded that the technical roadmap of IFC-based data interoperability is not feasible. According to this interoperability experiment, using the proposed IFC Platform for data interoperability has a good performance. Based on IFC schema, a set of data dictionaries were developed in the proposed platform for fully supporting information from diverse disciplines. The results demonstrate that using the IFC-based BIM platform for data interoperability is feasible in practice. Hence, a suggested method was proposed for improving data interoperability: during data sharing and exchange between heterogeneous software tools, a common BIM platform which fully supports IFC schema is suggested to integrate models from multiple disciplines.

Additionally, some limitations and other work are going to be addressed by future research and development:

- This experiment is limited to a case study with the use of limited test objects and specific software tools. To further analyze interoperability issues in the AEC/ FM industry, more objects for specific data exchanges will be tested by using more software tools in the future work.

- Most software tools interpret IFC model data depending on their own mapping mechanisms, resulting in multiple mappings for the same information. The method to standardize these mappings needs to be studied. A typical example is the colour, where five representation methods are found in all test objects. 
- The ontology provides necessary semantics for domain knowledge and facilitates the reusability and integration. It is useful to enable data interoperability between heterogeneous BIM software. Hence, the data dictionary based on the ontology is considered in the future work.

\section{Acknowledgements}

This work was supported by the National Key Technologies Research and Development Program of China during the 13th Five-Year Plan Period under Grant 2016YFC0702001. This support is gratefully acknowledged.

\section{Author Contributions}

Huahui LAI and Xueyuan DENG conceived the study "Interoperability Analysis of IFC-based Data Exchange between Heterogeneous BIM Software". With the help of Xueyuan DENG, Huahui LAI designed conducted the interoperability experiment for IFC data exchange between BIM software tools. According to experiment results, Huahui LAI and Xueyuan DENG were responsible for interoperability analysis at the IFC data level. Finally, Huahui LAI wrote the first draft of the manuscript, and Xueyuan DENG revised it for publication.

\section{Funding}

This work was supported by the National Key Technologies Research and Development Program of China during the 13th Five-Year Plan Period under Grant 2016YFC0702001.

\section{Disclosure Statement}

The authors declare that they do not have any competing financial, professional, or personal interests from other parties.

\section{References}

BuildingSMART. 2010. IFC2x3 coordination view version 2.0 certification workflow [online], [cited 20 May 2018]. Available from Internet: http://www.buildingsmart-tech.org/certification/documents/bSI IFC Certification 2-0 Workflow CVV2.0_Draft1.1.pdf

BuildingSMART. 2013. List of software claiming IFC support [online], [cited 20 May 2018]. Available from Internet:

http://www.buildingsmart-tech.org/implementation/implementations

BuildingSMART. 2018. List of software participating in IFC certification [online], [cited 20 May 2018]. Available from Internet: http://www.buildingsmart-tech.org/certification/ifccertification-2.0/ifc2x3-cv-v2.0-certification/participants

Chen, D.; Doumeingts, G.; Vernadat, F. 2008. Architectures for enterprise integration and interoperability: Past, present and future, Computers in Industry 59(7): 647-659.

https://doi.org/10.1016/j.compind.2007.12.016
Choi, J. S.; Kim, I. H. 2011. Interoperability tests between IFC certified software for open BIM based quality assurance, in Proceedings of the $28^{\text {th }}$ International Symposium on Automation and Robotics in Construction, 29 June - 2 July 2011, Seoul, Korea. https://doi.org/10.22260/ISARC2011/0240

Eastman, C.; Teicholz, P.; Sacks, R.; Liston, K. 2011. BIM handbook: A guide to building information modeling for owners, managers, designers, engineers and contractors. $2^{\text {nd }} \mathrm{ed}$. New York: Wiley.

Golabchi, A.; Kamat, V. R. 2013. Evaluation of industry foundation classes for practical building information modeling interoperability, in Proceedings of the $30^{\text {th }}$ International Symposium on Automation and Robotics in Construction and Mining, 11-15 August 2013, Montreal, Canada. https://doi.org/10.22260/ISARC2013/0003

Hu, Z. Z.; Tian, P. L.; Li, S. W.; Zhang, J. P. 2017. BIM-based integrated delivery technologies for intelligent MEP management in the operation and maintenance phase, Advances in Engineering Software 115: 1-16.

https://doi.org/10.1016/j.advengsoft.2017.08.007

Jeong, Y. S.; Eastman, C. M.; Sacks, R.; Kaner, I. 2009. Benchmark tests for BIM data exchanges of precast concrete, Automation in Construction 18(4): 469-484.

https://doi.org/10.1016/j.autcon.2008.11.001

Kam, C.; Fischer, M.; Hanninen, R.; Lehto, S.; Laitinen, J. 2002. Implementation challenges and research needs of the IFC interoperability standard: Experiences from HUT-600 construction pilot, in Proceedings of the International Workshop on Information Technology in Civil Engineering: Computing in Civil Engineering, 2-3 November 2002, Washington, DC, USA, 211-220. https://doi.org/10.1061/40652(2003)18

Karan, E. P.; Irizarry, J. 2015. Extending BIM interoperability to preconstruction operations using geospatial analyses and semantic web services, Automation in Construction 53: 1-12. https://doi.org/10.1016/j.autcon.2015.02.012

Kim, K.; Yu, J. 2016. A process to divide curved walls in IFC-BIM into segmented straight walls for building energy analysis, Journal of Civil Engineering and Management 22(3): 333-345. https://doi.org/10.3846/13923730.2014.897975

Kiviniemi, A. 2008. IFC certification process and data exchange problems, in Proceedings of the $7^{\text {th }}$ European Conference on Product and Process Modelling, 10-12 September 2008, Nice, France.

Kiviniemi, A.; Tarandi, V.; Karlshøj, J.; Bell, H.; Karud, O. J. 2008. Review of the development and implementation of IFC compatible BIM. Erabuild project report.

Lee, G. 2011. What information can or cannot be exchanged?, Journal of Computing in Civil Engineering 25(1): 1-9. https://doi.org/10.1061/(ASCE)CP.1943-5487.0000062

Lee, G.; Won, J.; Ham, S.; Shin, Y. 2011. Metrics for quantifying the similarities and differences between IFC files, Journal of Computing in Civil Engineering 25(2): 172-181. https://doi.org/10.1061/(ASCE)CP.1943-5487.0000077

Liao, L.; Teo, E. A. L. 2017. Critical success factors for enhancing the building information modelling implementation in building projects in Singapore, Journal of Civil Engineering and Management 23(8): 1029-1044. https://doi.org/10.3846/13923730.2017.1374300

Lipman, R.; Palmer, M.; Palacios, S. 2011. Assessment of conformance and interoperability testing methods used for construction industry product models, Automation in Construction 20(4): 418-428. https://doi.org/10.1016/j.autcon.2010.11.011 
Ma, H.; Ha, E.; Chung, J.; Amor, R. 2006. Testing semantic interoperability, in Proceedings of Joint International Conference on Computing and Decision Making in Civil and Building Engineering, 14-16 June 2006, Montreal, Canada, 1216-1225.

Muller, M. F.; Garbers, A.; Esmanioto, F.; Huber, N.; Loures, E. R.; Canciglieri, O. 2017. Data interoperability assessment though IFC for BIM in structural design - a five-year gap analysis, Journal of Civil Engineering and Management 23(7): 943-954. https://doi.org/10.3846/13923730.2017.1341850

National Institute of Standards and Technology. 2011. IFC file analyser [online], [cited 20 May 2018]. Available from Internet: https://www.nist.gov/services-resources/software/ifc-fileanalyzer

Nizam, R. S.; Zhang, C. 2015. Current state of information exchange between the two most popular BIM software: Revit and Tekla, in Proceedings of the $1^{\text {st }}$ International Conference on Sustainable Buildings and Structures, 29-31 October 2015, Suzhou, China.

Oh, M.; Lee, J.; Hong, S. W.; Jeong, Y. 2015. Integrated system for BIM-based collaborative design, Automation in Construction 58: 196-206. https://doi.org/10.1016/j.autcon.2015.07.015

Olawumi, T. O.; Chan, D. W. M.; Wong, J. K. W. 2017. Evolution in the intellectual structure of BIM research: A bibliometric analysis, Journal of Civil Engineering and Management 23(8): 1060-1081. https://doi.org/10.3846/13923730.2017.1374301

Oleary, M. L. 2015. A first course in mathematical logic and set theory. New York: Wiley.

Pazlar, T.; Turk, Z. 2008. Interoperability in practice: Geometric data exchange using the IFC standard, Electronic Journal of Information Technology in Construction 13: 362-380.

Ramaji, I. J.; Memari, A. M. 2016. Interpreted information exchange: Systematic approach for BIM to engineering analysis information transformations, Journal of Computing in Civil Engineering 30(6): 04016028.

https://doi.org/10.1061/(ASCE)CP.1943-5487.0000591

Ramaji, I. J.; Memari, A. M. 2018. Extending the current model view definition standards to support multi-storey modular building projects, Architectural Engineering and Design Management 14: 158-176. https://doi.org/10.1080/17452007.2017.1386083

Sanguinetti, P.; Abdelmohsen, S.; Lee, J.; Lee, J.; Sheward, H.; Eastman, C. 2012. General system architecture for BIM: An integrated approach for design and analysis, Advanced Engineering Informatics 26(2): 317-333. https://doi.org/10.1016/j.aei.2011.12.001

Shi, X.; Liu, Y. S.; Gao, G.; Gu, M.; Li, H. J. 2018. IFCdiff: A content-based automatic comparison approach for IFC files, Automation in Construction 86: 53-68. https://doi.org/10.1016/j.autcon.2017.10.013

Sibenik, G. 2016. Building information modelling based interdisciplinary data exchange: A case study, in The $1^{\text {st }}$ International UK BIM Academic Forum Conference, 13-15 September 2016, Glasgow, Scotland.

Smith, D. K.; Tardiff, M. 2009. Building information modeling: A strategic implementation guide for architects, engineers, constructors and real estate asset managers. New York: Wiley. https://doi.org/10.1002/9780470432846

Taher, A. A. 2016. BIM software capability and interoperability analysis: An analytical approach toward structural usage of BIM software (S-BIM): Ms thesis. Royal Institute of Technology, Stockholm, Sweden.
Tolman, F. 1999. Product modeling standards for the building and construction industry: Past, present, and future, Automation in Construction 8(3): 227-235.

https://doi.org/10.1016/S0926-5805(98)00073-9 